\title{
Using a linguistic scorecard for peer-assessment through an on-line system
}

\section{Multiple criteria multiple peer-assessment with linguistic inputs}

\author{
Pasi Luukka and Mikael Collan \\ School of business \\ Lappeenranta University of Technology \\ Lappeenranta, Finland \\ pasi.luukka@lut.fi, mikael.collan@lut.fi
}

\begin{abstract}
Peer-assessment is a way to include evaluation as a part of the learning process and simultaneously to cut teacher load in grading of assignments. eLearning systems can be used to automate peer-assessment to a large extent. Peer-assessment benefits from multiplepeer-assessment as it is likely to even-out outliers. Linguistic scorecards can be used to simplify assessment. The linguistic scales can be mapped to fuzzy scales and the results weighted and aggregated to derive an overall assessment. Sometimes ranking of the outcomes is needed. This paper presents the foundations of a system that uses linguistic scorecards in peer-assessment that uses self-evaluation in weighting results, and that ranks the assessments. A numerical example is used to illustrate the system.
\end{abstract}

Keywords: Peer-assessment, linguistic variables, scorecard, Fuzzy OWA

\section{Introduction}

Having students perform peer assessment is known from previous research to have an important influence on learning $[1,2]$. Recommendations of involving students in assessment and feedback can be frequently found in the higher education literature [2-4]. The online environment and various eLearning platforms allow for a high level of automation of tasks with regards to assessment, such as easy collection of answers, anonymization of results, and the possibility to create tools for collecting assessments [5]. Using assignments, exercises, and essays are a natural part of eLearning as the face-to-face interaction is often limited. Tools that facilitate the administration and increase the learning effect of these are most likely to be well received.

The focus in this paper is presenting/proposing a linguistic scorecard-based system to assist student peer assessment, and to further allow an intelligent automatic aggregation of multiple assessments and the ranking of the aggregation results. Use of linguistic scales allows for the creation of an intuitively understandable, self-explanatory ranking tool - a scorecard that allows for estimation imprecision to be taken into consideration. The mapping of the linguistic terms to fuzzy numbers allows a precise representation of the imprecise information.

When one is designing the linguistic terms in student peer evaluation and "tuning" the mapping of the terms to the fuzzy numbers, it is important that one is aware of the context. The correct assignment of terms to fuzzy scales may allow, for example, for the assessment of items with different difficulty and thus different scales to be accommodated by the structure of the mapping. Here the details of mapping are left outside the focus of the paper.

Having students perform peer assessment one may benefit from multiple peers assessing each object (assignment / exercise): if the assessments differ radically from each other it may be used as a signal of the need for a moderator (teacher) to have a look at the object, and perhaps perform the assessment. Using multiple peers also allows for the inclusion of multiple points-of-view.

When multiple (linguistic, fuzzy) evaluations are performed the assessments will need to be aggregated and perhaps weighted. We propose that weighting students' evaluations is done by assigning the weights to each student's evaluation based on their selfevaluation in the "fact-based parts" of the same task. This means that an assessment by a student who reports good knowledge of the factual content of an assignment will receive a higher weight, than an assessment by a student reporting low knowledge.

The multiple assessments must be aggregated to yield an overall assessment that will then serve in the grading of the performance of the students; most usually this means defuzzification of the overall assessment to yield a crisp pointage of the assessment used as a part of a course evaluation. If the best performance is rewarded (for example, with extra points towards the test) the overall assessments must be ranked. This means ranking the fuzzy overall assessments.

Figure 1 shows a lay-out for the proposed system that includes the above-mentioned components of peerassessment, result aggregation, and overall result ranking. 


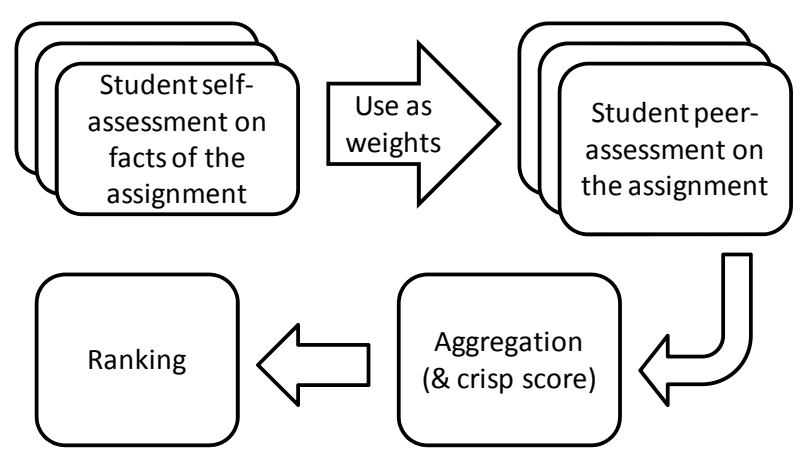

Fig. 1: Blue-print of a proposed peer-assessment system

This paper continues as follows: in the following section the mathematical background is introduced, then a numerical example of a peer assessment situation with the proposed tool is presented, finally the paper is closed with conclusions and discussion.

\section{Mathematical background}

In the following some basic definitions, related to the concepts that are essential to the proposed fuzzy (multiple criteria, multiple peer) assessment support method are reviewed.

It is supposed that the linguistic scales used in the scorecards are mapped to fuzzy scales that use triangular fuzzy numbers for representing each linguistic variable.

Definition 1. A triangular fuzzy number $A$ can be defined by a triplet $A=\left(a_{1}, a_{2}, a_{3}\right)$. The membership function $\mu_{\mathrm{A}}(\mathrm{x})$ is defined as [6]

$$
\mu_{A}(x)=\left\{\begin{array}{lc}
0, & x<a_{1} \\
\frac{x-a_{1}}{a_{2}-a_{1}}, & a_{1} \leq x \leq a_{2} \\
\frac{x-a_{3}}{a_{2}-a_{3}}, & a_{2} \leq x \leq a_{3} \\
0, & x>a_{3}
\end{array}\right.
$$

Definition 2. The $\alpha$-cut of fuzzy number A is defined as

$$
A^{\alpha}=\left\{x_{i} \mid \mu_{A}\left(x_{i}\right) \geq \alpha, \quad x_{i} \in X\right\}(2)
$$

where $\alpha \in[0,1]$.

$\mathrm{A}^{\alpha}$ is a non-empty bounded closed interval contained in $\mathrm{X}$ and it can be denoted by $A^{\alpha}=\left[a_{l}(\alpha), a_{r}(\alpha)\right]$.

For arithmetic operations for triangular fuzzy numbers we refer to [6]. One of the essential concepts that are used is the Fuzzy Ordered Weighted Averaging (FOWA) operator [7-9]. The FOWA operator is an aggregation operator that is here proposed to be used in the aggregation of the multiple linguistic fuzzy assessments.
Definition 3. Let $U$ be the set of fuzzy numbers. A FOWA operator of dimension $n$ is a mapping FOWA: $U^{n} \rightarrow U$ that has an associated weighting vector $W$ of dimension $n$ such that the sum of the weights is 1 and $w_{i} \in[0,1]$, then:

$$
\operatorname{FOWA}\left(\hat{a}_{1}, \hat{a}_{2}, \cdots, \hat{a}_{n}\right)=\sum_{i=1}^{n} w_{i} b_{i}(3)
$$

where $b_{i}$ is the $i$ th largest of the $\left(\hat{a}_{1}, \hat{a}_{2}, \cdots, \hat{a}_{n}\right)$, which are now fuzzy triangular numbers of form definition 1 . FOWA will be applied later on in the aggregation over all the criteria in the decision matrix. Next, the attention is turned to two important issues of FOWA 1) how to form the weighting vector, and 2) how to form the ordering needed for fuzzy numbers.

One of the most important issues of the theory of OWA operators is the determination of the associated weights in the weighting vector $W$. There are a number of approaches, for the development of the weights in the weighting vector, for example $[10,11]$. One of the first methodologies for obtaining the weights was introduced in 1988 by O'Hagan [12]. His approach assumed that in the aggregation procedure one have predefined degree of orness, $\alpha$, and then the weights are calculated in a manner that maximizes the entropy $-\sum_{i=1}^{n} w_{i} \cdot \ln \left(w_{i}\right)$. Algorithmically the solution is based on the constrained optimization problem. Mathematically it is:

$$
\begin{aligned}
& \text { Maximize }-\sum_{i=1}^{n} w_{i} \cdot \ln \left(w_{i}\right) \\
& \text { subject to } \alpha=\frac{1}{n-1} \sum_{i=1}^{n}(n-i) \cdot w_{i}, \\
& \sum_{i=1}^{n} w_{i}=1, \quad w_{i} \in[0,1]
\end{aligned}
$$

There are many possibilities on how to solve this optimization problem. One is to use the method of Lagrange multipliers. In 2001, Fuller and Majlender [13] introduced the analytical solution to the above mentioned problem. They presented the following results:

1) if $n=2$, then $w_{1}=\alpha$ and $w_{2}=1-\alpha$,

2) if $\alpha=0$ or $\alpha=1$, then weighting vectors are $w=(0, \ldots, 1)$ or $w=(1,0, \ldots, 0)$.

3) if $n \geq 3$ and $0 \leq \alpha \leq 1$, then

$$
\begin{gathered}
w_{j}=\left(w_{1}^{n-j} \cdot w_{n}^{j-1}\right)^{\frac{1}{n-1}}, \\
w_{n}=\frac{((n-1) \cdot \alpha-n) \cdot w_{1}+1}{(n-1) \cdot \alpha+1-n \cdot w_{1}} \\
w_{1}\left[(n-1) \cdot \alpha+1-n \cdot w_{1}\right]^{n}=((n-1) \cdot \alpha)^{n-1} \cdot\left[((n-1) \cdot \alpha-n) \cdot w_{1}+1\right]
\end{gathered}
$$

Basically for obtaining the weights in a case, where $n>2$, the first step should be determining the first 
weight. After that one can calculate the last weight of the weighting vector, and then the other weights.

The FOWA operator also requires ordering of fuzzy numbers, and the selection of the ordering method to be used is the next step: this paper uses the method proposed by Kaufmann and Gupta in [14].

A linear order of the fuzzy numbers can be found by focusing on selected properties fuzzy numbers, and using them as ordering criteria. If the first selected criterion does not give a unique linear order, then a second criterion should be used, and so forth. Next, three different criteria for ordering, used in this paper are presented:

(i) First criterion, removal: Let us consider an ordinary number $k \in R$ and a fuzzy number $A$. The left side removal of $A$ with respect to $k$, denoted by $R_{l}(A, k)$, is defined as the area bounded by $k$ and the left side of the fuzzy number $A$. Similarly, the right side removal, $R_{r}(A, k)$ is defined. The removal of the fuzzy number $A$ with respect to $k$ is defined as the mean of $R_{l}(A, k)$ and $R_{r}(A, k)$. Thus,

$$
R(A, k)=\frac{1}{2}\left(R_{l}(A, k)+R_{r}(A, k)\right)(6)
$$

The position of $k$ can be located anywhere on the $x$ axis including $k=0$. The areas, by definition, are positive quantities, but here they are evaluated by integration taking into account the position (negative, zero, or positive) of the variable $x$; therefore, $R(A, k)$ can be positive, negative or null.

Two different fuzzy numbers can have the same removal with respect to the same $k$. In fact, this criterion decomposes a set of fuzzy numbers into classes having the same removal number. If the origin 0 is conveniently moved to the left, it is possible, in this case that all of the fuzzy numbers will have positive removal numbers. Hence, the removal numbers become positive if $k$ is correctly chosen. The removal number with respect to a given $k$, therefore, can be taken as a measure of distances, and can thus be used for ordering the fuzzy numbers. The removal number $R(A, k)$ defined in this criterion, relocated to $k=0$ is equivalent to an "ordinary representative" of the fuzzy number. In the case of a triangular fuzzy number this ordinary representative is given by

$$
\tilde{A}=\frac{a_{1}+2 a_{2}+a_{3}}{4}
$$

where $A=\left(a_{1}, a_{2}, a_{3}\right)$.

(ii) Second criterion, mode: In each class of fuzzy numbers one should look for the mode, and these modes will generate sub-classes. If the fuzzy numbers under consideration have a non-unique mode, one takes the mean position of the modal values. It must be noted that this is only one way of obtaining sub-classes, and one may need the following third divergence criterion for further sub-classification.

(iii) Third criterion, divergence: If the divergence around the mode is considered for each sub-class, subsub-classes can be obtained, and this criterion may be sufficient to obtain the final linear ordering of fuzzy numbers.

When one orders fuzzy numbers to size order, one proceeds as follows: apply the above presented criteria in the order (i)-(ii)-(iii), such that if a unique linear order is not obtained, then use the next criterion.

\subsection{Proposed method}

The following general situation is considered, where a finite set of projects $P=\left\{P_{i} \mid i=1, \cdots, m\right\}$ exists that need to be evaluated by a committee of decisionmakers $D=\left\{D_{l} \mid l=1,2, \ldots, k\right\}$, by considering a finite set of given criteria $C=\left\{C_{j} \mid j=1,2, \ldots, n\right\}$. A decision matrix representation of performance rating of each alternative project $\mathrm{P}_{\mathrm{i}}$ is considered, with respect to each criterion $C_{j}$ as follows:

$$
X_{l}=\left[\begin{array}{ccc}
x_{11} & \cdots & x_{1 n} \\
\vdots & \ddots & \vdots \\
x_{m 1} & \cdots & x_{m n}
\end{array}\right]
$$

where $m$ lines represent $m$ possible projects, $n$ columns represents $n$ relevant criteria and $x_{i j}$ represents the performance rating of the $i$-th project with respect to $j$-th criterion $C_{j}$. These ratings are collected by using fuzzy scorecards, and are triangular fuzzy numbers.

The above fuzzy decision matrix is formed for each decision maker $D_{l}$. These decision matrices are then weighted according to evaluated competences of the decision makers from the particular subjects.

$$
V_{l}=\left(v_{i j}\right)_{m \times n}
$$

where $v_{i j}=x_{i j} \cdot w_{j}$.

To aggregate the fuzzy decision matrices from each decision maker to one single decision matrix, the aggregation method proposed in [15] is used, where aggregated triangular fuzzy number $R=(a, b, c)$ is calculated using $a=\frac{\min \left\{a_{l}\right\}}{l}, b=\frac{1}{k} \sum_{l=1}^{k} b_{l}, c=$ $\max \{c\}$. This way aggregated fuzzy ratings $\mathrm{x}_{\mathrm{ij}}$ of projects with respect to each criterion are now $x_{i j}=$ $\left(a_{i j}, b_{i j}, c_{i j}\right)$, where $a_{i j}=\min _{l}\left\{a_{i j l}\right\}, b_{i j}=\frac{1}{k} \sum_{l=1}^{k} b_{i j l}$, $c_{i j}=\max _{l}\left\{c_{i j l}\right\}$.

The next step for the decision matrix is to form a linear scale transformation to transform the various criteria scales into comparable scales. The criteria set can be divided into a benefit criteria (larger the rating, the greater the preference) and a cost criteria (the smaller the rating, the greater the preference). Therefore, the normalized fuzzy decision matrix can be represented as

$$
R=\left(r_{i j}\right)_{m \times n}
$$

where $\mathrm{B}$ and $\mathrm{C}$ are the sets of benefit criteria and cost criteria, respectively, and 


$$
\begin{aligned}
& r_{i j}=\left(\frac{a_{i j}}{c_{j}^{\oplus}}, \frac{b_{i j}}{c_{j}^{\oplus}}, \frac{c_{i j}}{c_{j}^{\oplus}}\right) \quad j \in B \\
& r_{i j}=\left(\frac{a_{j}^{\ominus}}{c_{i j}}, \frac{a_{j}^{\ominus}}{b_{i j}}, \frac{a_{j}^{\ominus}}{a_{i j}}\right) \quad j \in C
\end{aligned}
$$

where $\quad c_{j}^{\oplus}=\max _{\mathrm{i}}\left(c_{i j}\right), j \in B \quad$ and $\quad a_{j}^{\ominus}=$ $\min _{\mathrm{i}}\left(a_{i j}\right), j \in C$.

This normalized decision matrix will then be aggregated with regards to criteria in the following way, by using FOWA.

$$
R_{i}=F O W A\left(r_{i 1}, r_{i 2}, \cdots, r_{i n}\right)=\sum_{j=1}^{n} w_{j} b_{j}
$$

where $b_{j}$ is the $j$-th largest of the vector $\left(r_{i 1}, r_{i 2}, \cdots, r_{i n}\right)$. Ordering is done by using the ordering method given by Kaufman and Gupta in [6], and shortly presented in previous subsection. In addition, O'Hagan's method is applied to generate the weights.

This results in a triangular fuzzy number for each alternative that is considered. Next step in the decision making process is the determination of the order of the resulting fuzzy numbers. This can be done, for example, by applying the ordering of fuzzy numbers again.

\section{Numerical example}

Each student has to anonymously assess three (same) essay assignments by their peers on a given topic, based on five criteria with a linguistic scorecard. Each essay will receive three assessments of which the scores are aggregated. All the essays need to be ranked based on the assessments, as a wanted number of best essays will receive extra points for the test. The required contents of the essay assignment have been well specified and are available for reference during the evaluation. In this numerical illustration only three assessed essays are used as an example; in reality there would be a larger number of essays. The hierarchical structure of this decision problem is shown in Fig 1. The proposed method is applied to solve the problem and computational procedure is summarized as follows:

Step 1: The assessment starts by the students' selfassessment on how well they fared on three fact-based issues that they are asked to peer assess. The three selfevaluation criteria are:

\section{1) How well did I understand and answer to issue 1 $\left(S C_{1}\right)$ \\ 2) How well did I understand and answer to issue 2 $\left(S C_{2}\right)$ \\ 3) How well did I understand and answer to issue 3 $\left(S C_{3}\right)$}

Self-assessment result is used in setting the weights for the assessments of the three first criteria of the peer assessment. Table 1 reports the self-assessments.

\begin{tabular}{|c|c|c|c|}
\hline & $\mathrm{SC}_{1}$ & $\mathrm{SC}_{2}$ & $\mathrm{SC}_{3}$ \\
\hline Student $_{1}$ & $(0.4,0.7,0.9)$ & $(0.7,0.9,1)$ & $(0.3,0.5,0.8)$ \\
\hline Student $_{2}$ & $(0.7,0.9,1)$ & $(0.9,1,1)$ & $(0.7,0.8,1)$ \\
\hline Student $_{3}$ & $(0.9,1,1)$ & $(0.5,0.7,0.8)$ & $(0.7,0.8,1)$ \\
\hline Sum $_{1-3}$ & $(2,2.6,2.9)$ & $(2.1,2.6,2.8)$ & $(1.7,2.1,2.8)$ \\
\hline
\end{tabular}

Table 1: Self-assessment scores and overall score

The self-assessment scores are scaled (or internally weighted) by dividing them with the sum of scores for each self-assessed criterion, see Table 2. Standard division of fuzzy numbers is used. The two remaining criteria $\left(\mathrm{C}_{3}\right.$ and $\left.\mathrm{C}_{4}\right)$ are not separately weighted.

\begin{tabular}{|c|c|c|c|}
\hline & $\mathrm{SC}_{1}$ & $\mathrm{SC}_{2}$ & $\mathrm{SC}_{3}$ \\
\hline Student $_{1}$ & $(0.14,0.27,0.45)$ & $(0.25,0.35,0.48)$ & $(0.11,0.24,0.48)$ \\
\hline Student $_{2}$ & $(0.24,0.35,5)$ & $(0.32,0.38,0.48)$ & $(0.25,0.38,0.59)$ \\
\hline Student $_{3}$ & $(0.31,0.38,0.5)$ & $(0.18,0.27,0.38)$ & $(0.25,0.38,0.59)$ \\
\hline
\end{tabular}

Table 2: Scaled self-assessment scores.

Step 2: The students perform peer-assessment of three essays by using a linguistic scorecard that uses (for example) five linguistic terms and considers five different criteria:

1) Correctness of the factual contents (issue 1) $\left(C_{1}\right)$

2) Correctness of the factual contents (issue 2) $\left(C_{2}\right)$

3) Correctness of the factual contents (issue 3) $\left(C_{3}\right)$

4) Logic of reaching, and sensibility of conclusions $\left(C_{4}\right)$

5) Quality of used language and understandability $\left(C_{5}\right)$

Peer-assessments of the alternatives with respect to each criterion are presented in Table 3.

\begin{tabular}{|c|c|c|c|c|c|}
\hline Peer1: & $\mathrm{C}_{1}$ & $\mathrm{C}_{2}$ & $\mathrm{C}_{3}$ & $\mathrm{C}_{4}$ & $\mathrm{C}_{5}$ \\
\hline $\mathrm{A}_{1}$ & $(4,7,9)$ & $(7,9,10)$ & $(3,5,8)$ & $(9,10,10)$ & $(3,5,6)$ \\
\hline $\mathrm{A}_{2}$ & $(7,9,10)$ & $(9,10,10)$ & $(7,8,10)$ & $(9,10,10)$ & $(8,9,10)$ \\
\hline $\mathrm{A}_{3}$ & $(9,10,10)$ & $(5,7,8)$ & $(7,8,10)$ & $(5,8,10)$ & $(7,9,10)$ \\
\hline Peer2: & $\mathrm{C}_{1}$ & $\mathrm{C}_{2}$ & $\mathrm{C}_{3}$ & $\mathrm{C}_{4}$ & $\mathrm{C}_{5}$ \\
\hline $\mathrm{A}_{1}$ & $(7,9,10)$ & $(4,7,9)$ & $(7,9,10)$ & $(7,9,10)$ & $(3,5,6)$ \\
\hline $\mathrm{A}_{2}$ & $(7,9,10)$ & $(9,10,10)$ & $(9,10,10)$ & $(9,10,10)$ & $(4,7,9)$ \\
\hline $\mathrm{A}_{3}$ & $(7,9,10)$ & $(7,9,10)$ & $(4,7,9)$ & $(9,10,10)$ & $(7,9,10)$ \\
\hline Peer3: & $\mathrm{C}_{1}$ & $\mathrm{C}_{2}$ & $\mathrm{C}_{3}$ & $\mathrm{C}_{4}$ & $\mathrm{C}_{5}$ \\
\hline $\mathrm{A}_{1}$ & $(4,7,9)$ & $(3,5,8)$ & $(7,9,10)$ & $(9,10,10)$ & $(3,5,6)$ \\
\hline $\mathrm{A}_{2}$ & $(4,7,9)$ & $(9,10,10)$ & $(7,9,10)$ & $(9,10,10)$ & $(7,9,10)$ \\
\hline $\mathrm{A}_{3}$ & $(3,5,8)$ & $(9,10,10)$ & $(9,10,10)$ & $(4,7,9)$ & $(4,7,9)$ \\
\hline
\end{tabular}

Table 3: Peer assessments of all 5 criteria.

Step 3: Formation of weighted decision matrices from peer-assessment, results are visible Table 4.

Step 4: Aggregation of decision matrices of the decision makers into one decision matrix, result visible Table 5.

Step 5: Calculation of normalized fuzzy decision matrices, visible in Table 6. 


\begin{tabular}{|c|c|c|c|c|c|}
\hline Peer1: & $\mathrm{C}_{1}$ & $\mathrm{C}_{2}$ & $\mathrm{C}_{3}$ & $\mathrm{C}_{4}$ & $\mathrm{C}_{5}$ \\
\hline $\mathrm{A}_{1}$ & $(0.6,1.9,4.1)$ & $(1.8,3.1,4.8)$ & $(0.3,1.2,3.8)$ & $(3,3.3,3.3)$ & $(1,1.7,2)$ \\
\hline $\mathrm{A}_{2}$ & $(1.0,2.4,4.5)$ & $(2.3,3.5,4.8)$ & $(0.8,2.1,4.7)$ & $(3,3.3,3.3)$ & $(2.7,3,3.3)$ \\
\hline $\mathrm{A}_{3}$ & $(1.2,2.7,4.5)$ & $(1.3,2.4,3.8)$ & $(0.8,1.9,4.7)$ & $(1.7,2.7,3.3)$ & $(2.3,3.0,3.3)$ \\
\hline Peer2: & $\mathrm{C}_{1}$ & $\mathrm{C}_{2}$ & $\mathrm{C}_{3}$ & $\mathrm{C}_{4}$ & $\mathrm{C}_{5}$ \\
\hline $\mathrm{A}_{1}$ & $(1.7,3.1,5.0)$ & $(1.3,2.7,4.3)$ & $(1.8,3.4,5.9)$ & $(2.3,3.0,3.3)$ & $(1.0,1.7,2.0)$ \\
\hline $\mathrm{A}_{2}$ & $(1.7,3.1,5.0)$ & $(2.9,3.8,4.8)$ & $(2.3,3.8,5.9)$ & $(3,3.3,3.3)$ & $(1.3,2.3,3)$ \\
\hline $\mathrm{A}_{3}$ & $(1.7,3.1,5.0)$ & $(2.3,3.5,4.8)$ & $(1.0,2.7,5.3)$ & $(3,3.3,3.3)$ & $(2.3,3,3.3)$ \\
\hline Peer3: & $\mathrm{C}_{1}$ & $\mathrm{C}_{2}$ & $\mathrm{C}_{3}$ & $\mathrm{C}_{4}$ & $\mathrm{C}_{5}$ \\
\hline $\mathrm{A}_{1}$ & $(1.2,2.7,4.5)$ & $(0.5,1.3,3.0)$ & $(1.8,3.4,5.9)$ & $(3,3.3,3.3)$ & $(1,1.7,2)$ \\
\hline $\mathrm{A}_{2}$ & $(1.2,2.7,4.5)$ & $(1.6,2.7,3.8)$ & $(1.8,3.4,5.9)$ & $(3,3.3,3.3)$ & $(2.3,3,3.3)$ \\
\hline $\mathrm{A}_{3}$ & $(0.9,1.9,4)$ & $(1.6,2.7,3.8)$ & $(2.3,3.8,5.9)$ & $(1.3,2.3,3)$ & $(1.3,2.3,3)$ \\
\hline
\end{tabular}

Table 4: Weighted peer assessment for all 5 criteria.

\begin{tabular}{|c|c|c|c|c|c|}
\hline & $\mathrm{C}_{1}$ & $\mathrm{C}_{2}$ & $\mathrm{C}_{3}$ & $\mathrm{C}_{4}$ & $\mathrm{C}_{5}$ \\
\hline $\mathrm{A}_{1}$ & $(0.6,2.6,5.0)$ & $(0.5,2.4,4.8)$ & $(0.3,2.7,5.9)$ & $(2.3,3.2,3.3)$ & $(1, .1 .7,2)$ \\
\hline $\mathrm{A}_{2}$ & $(1.0,2.7,5.0)$ & $(1.6,3.3,4.8)$ & $(0.8,3.1,5.9)$ & $(3,3.3,3.3)$ & $(1.3,2.8,3.3)$ \\
\hline $\mathrm{A}_{3}$ & $(0.9,2.6,5.0)$ & $(1.3,2.9,4.8)$ & $(0.8,2.8,5.9)$ & $(1.3,2.8,3.3)$ & $(1.3,2.8,3.3)$ \\
\hline
\end{tabular}

Table 5: Aggregated decision matrix of the peer-assessments

\begin{tabular}{|c|c|c|c|c|c|}
\hline & $\mathrm{C}_{1}$ & $\mathrm{C}_{2}$ & $\mathrm{C}_{3}$ & $\mathrm{C}_{4}$ & $\mathrm{C}_{5}$ \\
\hline $\mathrm{A}_{1}$ & $(0.11,0.51,1)$ & $(0.11,0.5,1)$ & $(0.05,0.46,1)$ & $(0.7,0.97,1)$ & $(0.3,0.5,0.6)$ \\
\hline $\mathrm{A}_{2}$ & $(0.19,0.55,1)$ & $(0.34,0.7,1)$ & $(0.13,0.53,1)$ & $(0.9,1,1)$ & $(0.4,0.83,1)$ \\
\hline $\mathrm{A}_{3}$ & $(0.19,0.52,1)$ & $(0.26,0.60,1)$ & $(0.13,0.47,1)$ & $(0.4,0.83,1)$ & $(0.4,0.83,1)$ \\
\hline
\end{tabular}

Table 6: Normalized decision matrix

Step 6: Aggregation of the decision matrix using FOWA over all criteria for each assignment (essay), with optimal weight for pre-chosen orness value, results visible in Table 7. In this example case $\alpha=0.7$.

\begin{tabular}{|c|c|}
\hline Candidate & FOWA $\left(\mathrm{C}_{1}, \mathrm{C}_{2}, \mathrm{C}_{3}, \mathrm{C}_{4}, \mathrm{C}_{5}\right)$ \\
\hline $\mathrm{A}_{1}$ & $(0.26,0.59,0.92)$ \\
\hline $\mathrm{A}_{2}$ & $(0.39,0.72,1)$ \\
\hline $\mathrm{A}_{3}$ & $(0.28,0.65,1)$ \\
\hline
\end{tabular}

Table 7: Aggregate assessment for the essays by using FOWA

Step 7: Defuzzification and scaling of the fuzzy numbers for each essay's peer-assessment for grading

The standard centroid of the area of triangular fuzzy numbers is used for the defuzzification. The resulting crisp number is scaled to interval $[0,5]$ and rounded to nearest integer for grading, see Table 8 for results. The scaling can be done to any scale needed.

\begin{tabular}{|c|c|c|}
\hline Candidate & Defuzzified no & scaled and rounded \\
\hline $\mathrm{A}_{1}$ & 0.586 & 3 \\
\hline $\mathrm{A}_{2}$ & 0.703 & 4 \\
\hline $\mathrm{A}_{3}$ & 0.639 & 3 \\
\hline
\end{tabular}

Table 8: Defuzzified and rounded grades

Step 8: Calculate overall rank of the assignments

The essay assignments are ranked by order them according to the aggregated (fuzzy number) assessments into a descending order by using removal, mode, and divergence, see Table 9. Using

\begin{tabular}{|c|l|l|l|l|}
\hline Essay & $\begin{array}{l}\text { Removal } \\
\text { no }\end{array}$ & divergence & mode & Order \\
\hline $\mathrm{A}_{1}$ & 0.59 & 0.66 & 0.59 & 3 \\
\hline $\mathrm{A}_{2}$ & 0.71 & 0.61 & 0.72 & 1 \\
\hline $\mathrm{A}_{3}$ & 0.64 & 0.72 & 0.65 & 2 \\
\hline
\end{tabular}

Table 9: Ranking the assignments 
Using this, the ranking $\mathrm{A}_{2}>\mathrm{A}_{3}>\mathrm{A}_{1}$ is obtained. Now, the essays have been graded and the wanted number of best essays can be selected for extra points.

\section{Summary and conclusions}

In this paper a multiple criteria multiple peer assessment system that is based on a scorecard with linguistic inputs was introduced. The proposed system is such that it can be used peer-assessment in on-line eLearning environments, and will assist trainers / teachers in (dramatically) reducing the workload connected to student assignments. It also allows the use of peer-evaluation to become a part of the learning process, an issue that is as important, or even more important, than the issue of facilitating assessment and reducing the work load for the teacher.

The linguistic scales used in the on-line scorecard are mapped to fuzzy scales. The resulting fuzzy assessments from each peer are combined into a decision making matrix. This matrix is weighted for each decision maker by a self-assessment of expertise. The decision matrices are combined into one matrix and the assessments are aggregated by FOWA. The well-known O'Hagan's method is used for the weighting of the criteria.

The FOWA operator is a relatively new method, and so far its usage in on-line peer-assessment systems has, to the best of our knowledge, not been studied. It differs from conventional aggregation operators in the sense that it aggregates fuzzy numbers instead of crisp numbers. The use of the method provided by Kaufman and Gupta with FOWA was proposed for ordering of fuzzy numbers.

As an avenue for further research, we observe that the problem of finding suitable total ordering is essential in this type of an approach, and that researching total ordering is an interesting future research direction.

\section{References}

[1] G. Gibbs, "How assessment frames student learning," in Innovative Assessment in Higher Education, C. Bryan and K. Clegg, Eds., ed London: Routledge, 2006.

[2] N. Falchikov, Improving assessment through student involvement: practical solutions for higher education teaching and learning. London: Routledge, 2004.

[3] A. Ljungman and C. Silén, "Examination involving students as peer examiners," Assessment \& Evaluation in Higher Education, vol. 33, pp. 289-300, 2008.

[4] F. Dochy, et al., "The use of self-, peer, and coassessment in higher education: a review," Studies in higher education, vol. 24, pp. 331-350, 1999.

[5] N. Trautmann, "Interactive learning through webmediated peer review of student science reports," Education Technology Research Development, vol. 57, pp. 685-704, 2009.

[6] M. Kaufmann and M. Gupta, Introduction to fuzzy arithmetic. New York, NY: Van Nostrand Reinhold, 1991.
[7] H. B. Mitchell and D. D. Estrach, "An OWA operator with fuzzy ranks," International Journal of Intelligent Systems, vol. 13, pp. 69-81, 1998.

[8] T. Calvo, et al., Aggregation operators: new trends and applications. New York: Physica-Verlag, 2002.

[9] G. Canfora and L. Troiano, "An Extensive Comparison between OWA and OFNWA Aggregation," in 8th SIGEF Conference, Napoli, Italia, 2001.

[10] D. Filev and R. Yager, "On the issue of obtaining OWA operator weights," Fuzzy Sets and Systems, vol. 94, pp. 157-169, 1998.

[11] Z. S. Zu, "An overview of methods for determining OWA weights," International Journal of Intelligent Systems, vol. 20, pp. 843-865, 2005.

[12] O'Hagan, "Aggregating template or rule antecedents in real time expert systems with fuzzy set logic," in 22nd Annual IEEE Asilomar Conference on Signals, Systems, and Computers Pacific Grove, CA, USA, 1988, pp. 681 - 689

[13] R. Fullér and P. Majlender, "An analytic approach for obtaining maximal entropy OWA operator weights," Fuzzy Sets and Systems, vol. 124, pp. 53-57, 2001.

[14] M. Kaufmann and M. Gupta, Fuzzy Mathematical Models in Engineering and Management Science: Elsevier Science Publishers B. V., 1988.

[15] C. T. Chen, et al., "A fuzzy approach for supplier evaluation and selection in supply chan management," International Journal of Production Economics, vol. 102, pp. 289-301, 2006. 